\title{
Mapping and Assessing Soil Sealing in Padua Municipality through Biotope Area Factor Index
}

\author{
Guglielmo Pristeri ${ }^{1}$, Francesca Peroni ${ }^{2}$, Salvatore Eugenio Pappalardo ${ }^{3, *}$, Daniele Codato ${ }^{3}$, \\ Anna Giulia Castaldo 1(D, Antonio Masi ${ }^{4}\left(\mathbb{D}\right.$ and Massimo De Marchi ${ }^{3}$ \\ 1 Department of Architecture and Urban Studies (DAStU), Polytechnic University of Milan, 20133 Milan, Italy; \\ guglielmo.pristeri@polimi.it (G.P.); annagiulia.castaldo@polimi.it (A.G.C.) \\ 2 Department of Historical and Geographic Sciences and the Ancient World (DiSSGeA), University of Padua, \\ 35100 Padova, Italy; francesca.peroni@dicea.unipd.it \\ 3 Department of Civil, Environmental and Architectural Engineering (ICEA), University of Padua, \\ 35100 Padova, Italy; daniele.codato@unipd.it (D.C.); massimo.demarchi@dicea.unipd.it (M.D.M.) \\ 4 Department of Agronomy, Food, Natural Resources, Animals and Environment (DAFNAE), University of \\ Padua, 35020 Padova, Italy; antonio.masi@unipd.it \\ * Correspondence: salvatore.pappalardo@unipd.it
}

Received: 12 May 2020; Accepted: 19 June 2020; Published: 24 June 2020 updates

\begin{abstract}
Soil sealing is a worldwide phenomenon of covering of natural or seminatural soil with impervious surfaces, such as built-up or paved surfaces. It is widely recognized as a major environmental issue which drives landscape fragmentation and ecosystem services degradation and loss. Italy is one of European countries with the highest extent of soil sealing. The most affected area is northern Italy, especially the Po Valley with more than $12 \%$ of sealed surfaces. According to official data, Veneto Region and the city of Padua are seriously affected by this phenomenon. The Biotope Area Factor is a consolidated ecological urban index for mapping soil sealing, adopted in different European cities to support urban planning; it expresses the ratio of the ecologically effective surface area in relation to the total land area according to land cover classes. The general aim of this study is to map and to assess soil sealing in the whole municipal territory of Padua using the Biotope Area Factor (BAF) index. We tested and adopted a digital land cover map together with aerial images to perform a BAF analysis on the whole municipal territory of Padua. By using sample areas previously analyzed, we validated our source data by a double spatial validation process; therefore, soil sealing analysis was scaled-up to the municipality territory. Results show that in the city of Padua, the average BAF index value is 0.6 ; totally permeable surfaces $(\mathrm{BAF}=1)$ cover $59.5 \%$, whereas totally "sealed" surfaces $(\mathrm{BAF}=0)$ are $40.3 \%$ of the municipal territory $\left(93 \mathrm{~km}^{2}\right)$. Most of the sealed soil is located in the east sector and in the historical core of the city, with BAF values ranging from 0 to 0.2 . A particularly critical area is identified within the new industrial area of the city, which is strongly affected by soil sealing. BAF maps are useful tools to identify critical areas by geovisualizing surface permeability at a very detailed scale and by enabling further analyses for hydrogeological risk assessment and urban climate regulation. Moreover, the use of BAF maps at urban scale today represent an important tool for urban management, especially for policy makers who are planning mitigation and compensation measures to control soil sealing.
\end{abstract}

Keywords: biotope area factor; land use-land cover; soil sealing; urban planning; urbanization 


\section{Introduction}

\subsection{Mapping and Assessing Soil Sealing in EU and Italy: State of the Art}

Soil sealing refers to the covering of pervious soil with totally impervious layers, like built-up or paved surfaces. It is a phenomenon mainly associated with processes of urbanization or land take [1] in which permeable soils are replaced by artificial, impermeable materials [2,3]. It is frequently influenced by demographic and/or economic factors and, in some countries, it often exceeds urban population growth rate $[4,5]$. Soil sealing is widely regarded as a major environmental issue, which is strictly related to important ecosystem services, especially in an urban context $[6,7]$.

Ecosystem services (ES) are the set of benefits that well-preserved ecosystems and natural environment provide to human communities [8,9]. They are classified in four categories by the UN Millennium Ecosystem Assessment (MA) [10], whereas the Common International Classification of Ecosystem Services (CICES) adopts a hierarchical system organized into five levels [11].

In particular, ES provided at urban or periurban scales (Urban Ecosystem Services, UES) and their mapping are considered as essential to investigate socioecological relationships and to preserve and improve resilience and sustainability of urban areas in an increasingly urbanized world [12,13].

Natural or seminatural soils, together with the vegetation they host, provide various ecosystem services, including carbon storage and sequestration, crop production, water cycle regulation, air purification, soil erosion control, habitat maintenance, pollination, and recreational and cultural experiences [14,15].

When a portion of land is sealed, its capacity to regulate the water cycle is heavily compromised and biodiversity values tend to decrease. As known, sealed soils are not suitable to host vegetation and therefore they are not capable to fulfil services like carbon sequestration, food production, and urban heat island mitigation [16]. Landscape fragmentation due to soil sealing also deprives citizens of physical and mental health benefits linked to the recreational use of green areas or other natural features [17]. Once soil sealing has occurred, it takes at least 15 years to restore previous biological and physicochemical conditions and the associated environmental benefits. Therefore, this process is usually not considered reversible [18].

Within countries of the European Union (EU), soil sealing has been monitored since 2006, firstly using statistical data (Land Use and Coverage Area frame Survey Program), then by means of Earth observation satellite imagery. In 2018, the Copernicus Land Monitoring Service (CLMC) performed a full reprocessing of the time series between 2006 and 2012 to harmonize the comparison, using an automatic derivation based on calibrated Normalized Difference Vegetation Index (NDVI). CLMC calculates imperviousness density by five strata representing percentages from $0 \%$ to $100 \%$. Results are provided as (i) primary products, namely imperviousness status layers with $20 \mathrm{~m}$ spatial resolution and aggregated $100 \mathrm{~m}$ resolution layers; and (ii) secondary products like imperviousness change layers, showing changes from 2006 to 2015 in a 3-year interval [19]. The European Environmental Agency (EEA) estimates that from 2009 to 2012 soil sealing in European countries involved a total of $2051 \mathrm{~km}^{2}$, an area comparable to the island of Tenerife [20].

The Copernicus Programme, through its Sentinel-2 mission, also supplies free satellite images at a geometric resolution of 10-20 m. The Italian Institute for Environmental Protection and Research (Istituto Superiore per la Protezione e la Ricerca Ambientale, ISPRA) currently adopts the Copernicus Programme products to primarily analyze soil sealing for the entire national territory.

ISPRA has been active for years in assessing soil sealing in Italy [21,22] and, since launch of the Copernicus Programme, adopted a methodology based on integration between Copernicus imagery classification and visual analysis of sample areas performed on high-resolution series of orthophotos [23]. The joint action between ISPRA and the Italian Regional Environmental Protection Agency (Agenzia Regionale per la Protezione Ambientale, or ARPA) has developed a land use change monitoring network which allows for the evaluation of soil sealing in Italy starting from the end of World War II, through a combination of historical maps, orthophotos, and remote sensing data [21]. 
In addition to official monitoring programs, independent studies and research tested procedures to assess soil sealing on sample areas at different scales. At a regional/territorial scale, most scholars [24-26] use supervised or unsupervised semiautomatic classification of satellite imagery, often developing multitemporal analyses to detect change in land use/land cover (LULC) and soil sealing due to urbanization. Some researchers enhance their workflow by applying a model builder in a GIS environment to calculate landscape ecology metrics [27]. Others [28,29] analyze land cover changes by performing spatial linear regressions on LULC classes.

When research is performed at a larger scale, e.g., in a city or a district, existing LULC maps or visual analysis on high resolution orthophotos can be used as input data to evaluate soil sealing [30,31]. A well-known urban index to classify soil sealing is the Biotope Area Factor (BAF), which was first applied in 1990 by Berlin Municipality [32] as a standard to foster sustainable urban planning. Since then, many similar indices were developed in other cities: Green Space Factor (GSF) in Malmö, Seattle Green Factor (SGF) in Seattle, and Biotope Area Index (BAI) in Seoul [33]. Our study uses the original version of BAF index (see Section 2.1).

Our study area, the city of Padua in Veneto region (Italy), shows a very high percentage of built-up areas, both in the ancient core and in more recently developed urban districts, so mapping and assessing soil sealing is crucial for urban sustainability and policy making. Hence, there is an urgent need for an accurate and site-specific assessment of pervious and impervious soils within the municipal territory.

\subsection{Aims of the Study}

The general aim of this study is to evaluate soil sealing at municipality level in Padua by adopting the Biotope Area Factor index. The specific aims are: (i) to test the reliability of an existing land use/land cover municipality map in order to calculate BAF values, (ii) to provide a powerful geovisualization of soil permeability in Padua by using a hexagon tessellation map, and (iii) to show possible case studies for BAF in urban planning and to sketch interdisciplinary connections for sustainable scenarios supported by the assessment of permeability in urban areas.

\section{Materials and Methods}

\subsection{Study Area}

According to EEA, Italy is one of the European countries which shows the largest extent of impervious surfaces. In 2017, the percentage of these surfaces in Italy was $7.65 \%$, i.e., $23,063 \mathrm{~km}^{2}$ [23]. The most affected area is northern Italy, especially the Po Valley; among regions, Lombardia and Veneto show the highest values, with more than $12 \%$ sealed surfaces. The other Italian regions show values lower than $10 \%$.

Padua is a city located in Veneto, in the Northeast of Italy (Figure 1), $35 \mathrm{~km}$ west of Venice. It lies south of the Alps on a plain that can be considered an extension of the Po Valley, the largest Italian plain. The municipality area (Figure 2) covers $93 \mathrm{~km}^{2}$ and, as of 2019, its population counts about 210,000 inhabitants [34].

The city has pre-Roman origins and is the seat of one of the oldest universities in the world, University of Padua. The urban shape has been marked historically by defending wall systems which acted as a border between built-up areas and surrounding countryside. The last wall system was constructed under Venetian rule in the 16th Century [35]. Starting from the end of the 19th Century, Padua expanded beyond its historical limits, with higher rates after World War II, due to demographic growth and new needs linked to economic and industrial development of its territory. New districts grew up north of the railway line and south of the Scaricatore water channel, and a large industrial area was built east of the city. Since the last decades of 20th Century, as in many other European cities, a lot of low-density residential buildings sprawled around the urban core at the expense of green or cultivated fields [36]. This caused the spread of mixed rural-urban neighborhoods, driven by the 
presence of industrial or commercial complexes and infrastructures. This process can also be noticed in the rest of the central Veneto area. Veneto is indeed, as stated above, one of the Italian regions with the highest values of soil sealing, namely $12.3 \%$ in 2017 according to ISPRA.

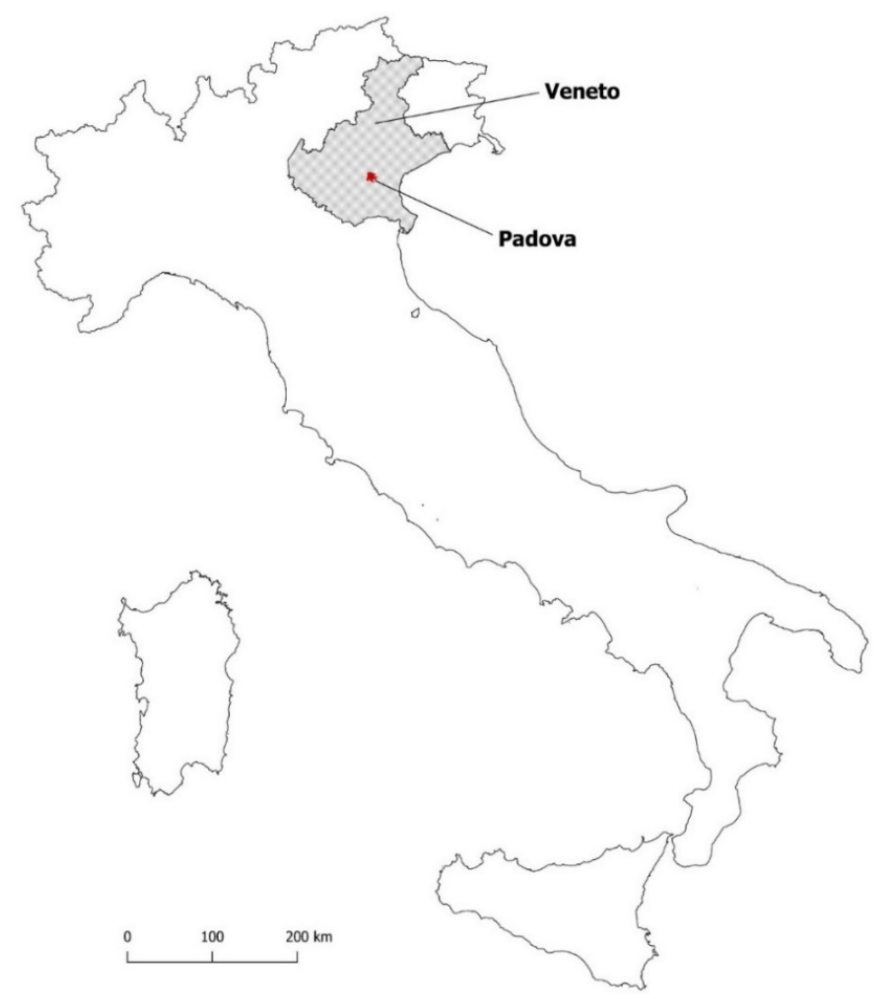

Figure 1. Geographical framework: location of Veneto and Padua (Padova) in Italy.

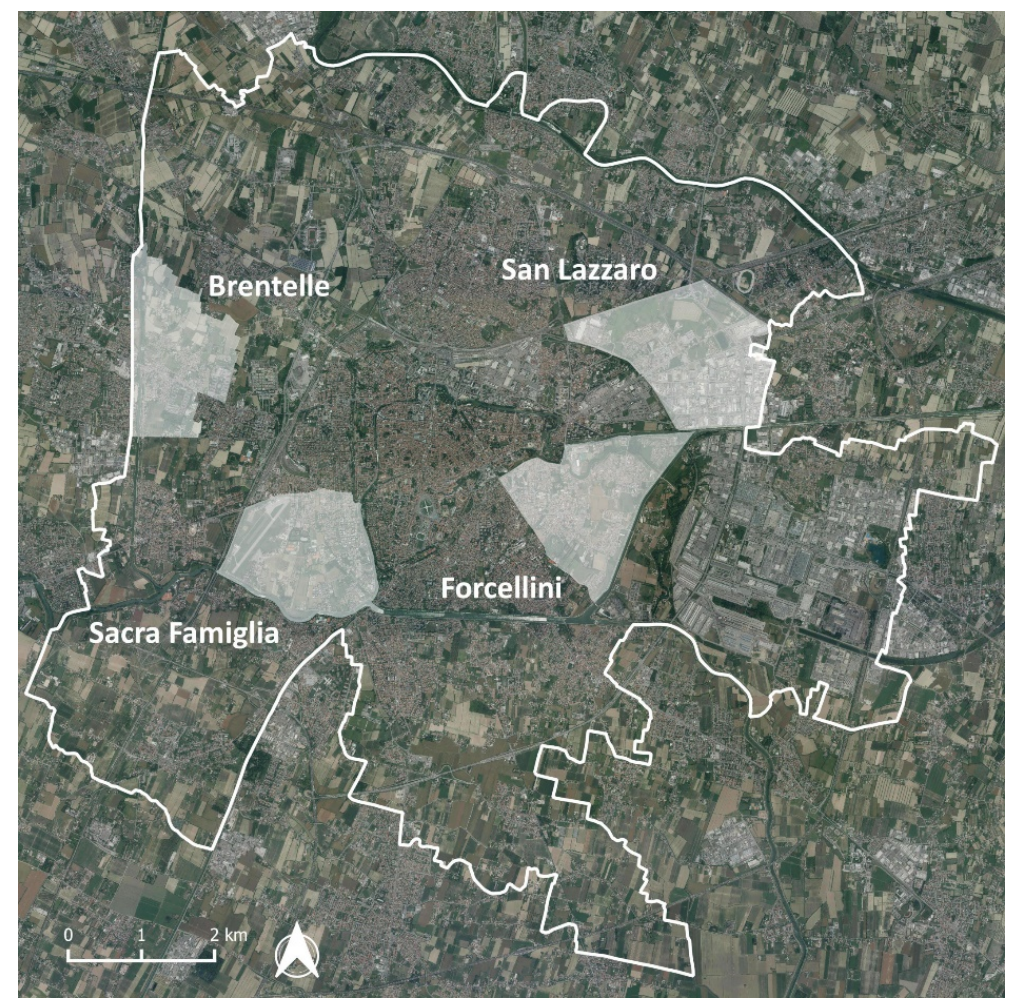

Figure 2. Padua municipality with the location of the four sample areas used for data validation. 


\subsection{The Biotope Area Factor: A Tool to Assess Urban Soil Sealing}

An effective tool to assess soil permeability and therefore to monitor soil sealing is the Biotope Area Factor (BAF), also known as Biotope Area Ratio [37]. It is an index developed for the first time by Berlin Municipality in 1990 in support of sustainable planning strategies. It expresses the ratio of the ecologically effective surface area to the total land area, through the following equation [30]:

$$
B A F=\frac{\sum_{i=1}^{n} A_{i} w_{i}}{\sum_{i=1}^{n} A_{i}}
$$

where $A_{i}$ corresponds to each homogeneous surface in terms of the BAF value and $w_{i}$ indicates the BAF coefficient (Equation (1)).

BAF assigns a weighting factor, representing ecological values related to perviousness, to every portion of a plot of land. Values range from total imperviousness (0) to total perviousness (1). Intermediate values depend on the depth of pervious soil covering. This classification method implies that soil perviousness is considered an essential requirement for an ecologically sustainable urban development [31].

In Berlin landscape plans, application of the BAF index can set a quantitative standard to observe for new architectural projects, which must comply with minimum values from 0.3 to 0.6 according to the planned use of new buildings and structures [32].

BAF values for different land cover types are displayed in the following scheme (Figure 3):

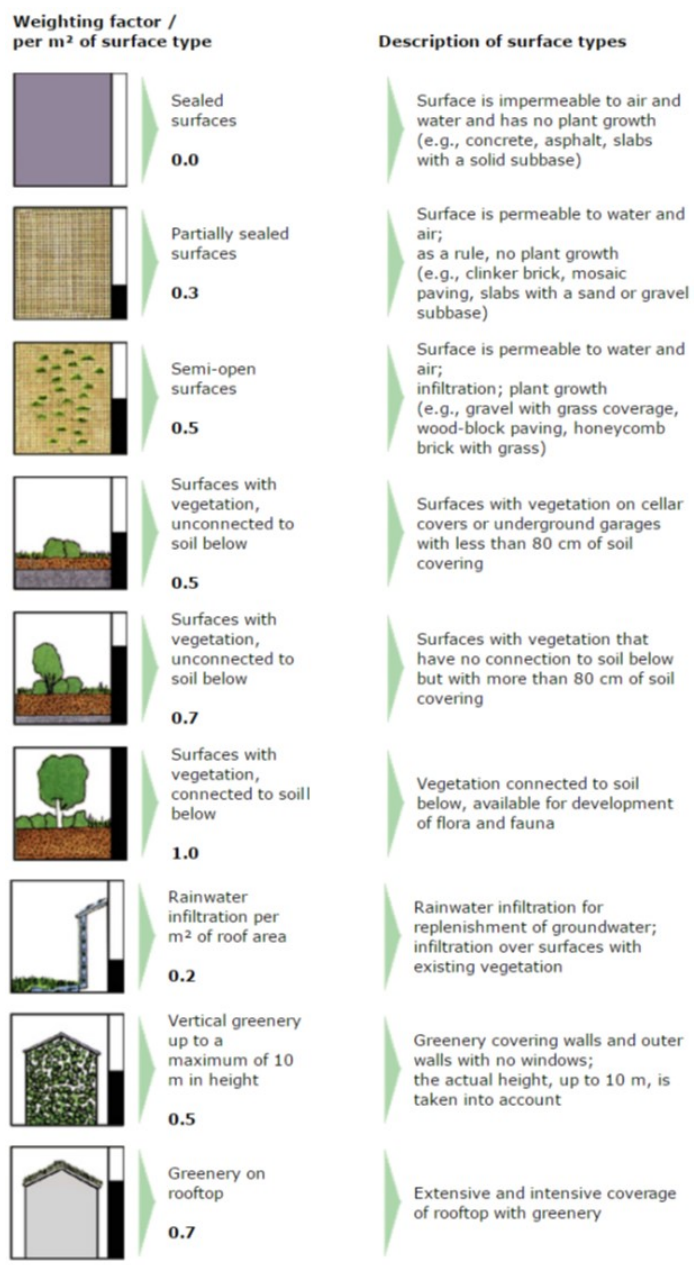

Figure 3. Biotope Area Factor (BAF) weights for different land cover types [31]. 


\subsection{Spatial Data}

The dataset used as a basis for data processing is the Topographic DataBase (DB) of Padua Municipality [38]. It is a LULC digital map based on photointerpretation of aerial imagery, where spatial features are represented as vector layers (lines, points, or polygons). This method of spatial data gathering and representation has been adopted by many Italian public administrations in recent years, inheriting purposes and functions of former topographic maps to comply with the policies of the EU INSPIRE directive [39]. The Topographic DB can be directly managed in a GIS environment. The information structure of the Padua Topographic DB includes three levels of two-digit codes defining the type of represented feature and a string identifying the specific feature.

The Padua Topographic DB is updated to 2013 [40], therefore the results achieved in our study may differ slightly from more recent assessments of soil sealing in the city of Padua. However, major spatial changes, such as new building complexes or roads, were manually reported to the DB prior to data processing, replacing the original geometries. Among the layers of the Topographic DB, only polygons were considered. Within them, there are overlaps of layers corresponding to different segmentations of some urban features; for example, the layer AR_STR representing streets is spatially equivalent to the sum of layers AC_CIC, AC_PED, AR_MARC, and SPART. For this reason, we made a selection of layers to avoid overlaps.

Input data were validated through a comparison of BAF values in four sample neighborhoods in Padua: Brentelle, Forcellini, Sacra Famiglia (also known as Basso Isonzo), San Lazzaro. At a neighborhood scale, BAF values were assigned to a detailed LULC map based on visual analysis of high-resolution $0.2 \mathrm{~m} /$ pixel orthophotos released in 2015 by Veneto Region [41].

At the end of the main workflow, two case studies of possible BAF applications in urban planning were sketched. In the first one, we performed an overlay analysis between pervious areas and a hydrogeological instability map from the Territorial Management Plan of Padua Municipality (Piano di Assetto del Territorio, PAT, whose current version dates to 2014 [42]). In the second case, areas with the highest perviousness values were overlapped with residential areas as shown in the Urban Development Plan for Padua (Piano degli Interventi, PI). This plan is updated in the case of changes in urban planning or the release of new planning tools [43]; in this study, we used a version adjusted in 2016 to match the territorial management plan.

The work was performed in a GIS environment using open source software QGIS 3.x and summarized in Figure 4.

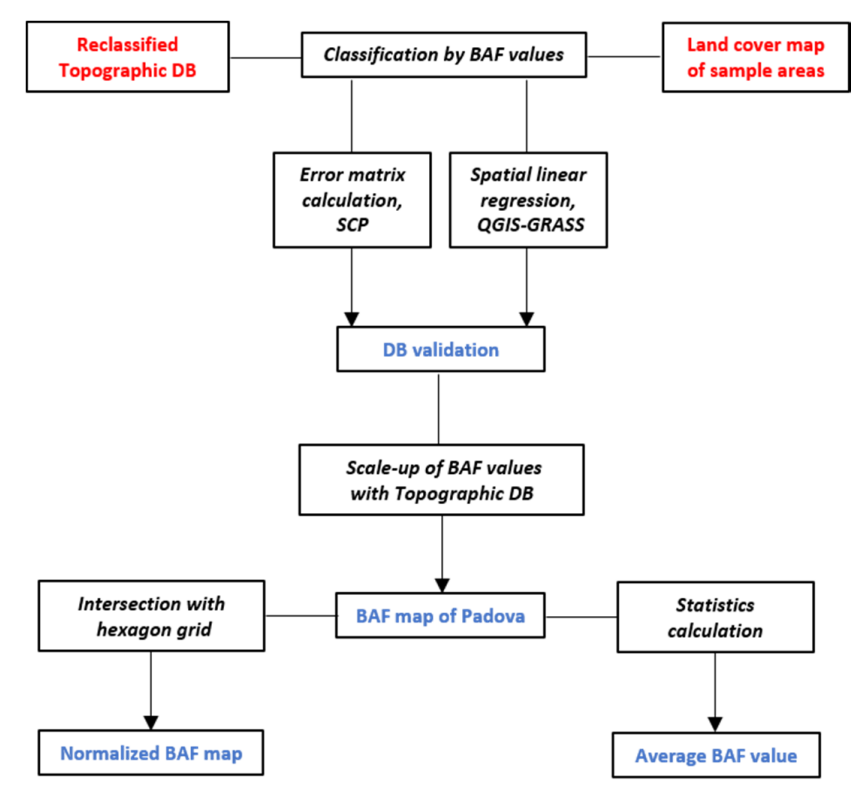

Figure 4. Flow chart of the main workflow ( $\mathrm{DB}=$ database; $\mathrm{SCP}=$ Semi-Automatic Classification Plugin) 


\subsection{From Topographic DataBase to BAF Maps}

Firstly, the 21 selected classes of the Topographic DB were merged into a unique polygon vector layer, maintaining all the attributes of the origin layers. Then, we performed geometry and topology checks and corrections to remove overlaps or other spatial flaws. After that, a simplified LULC category with its proper BAF value was assigned to each class of the DB (Table 1). The resulting LULC map of Padua is shown in Figure 5.

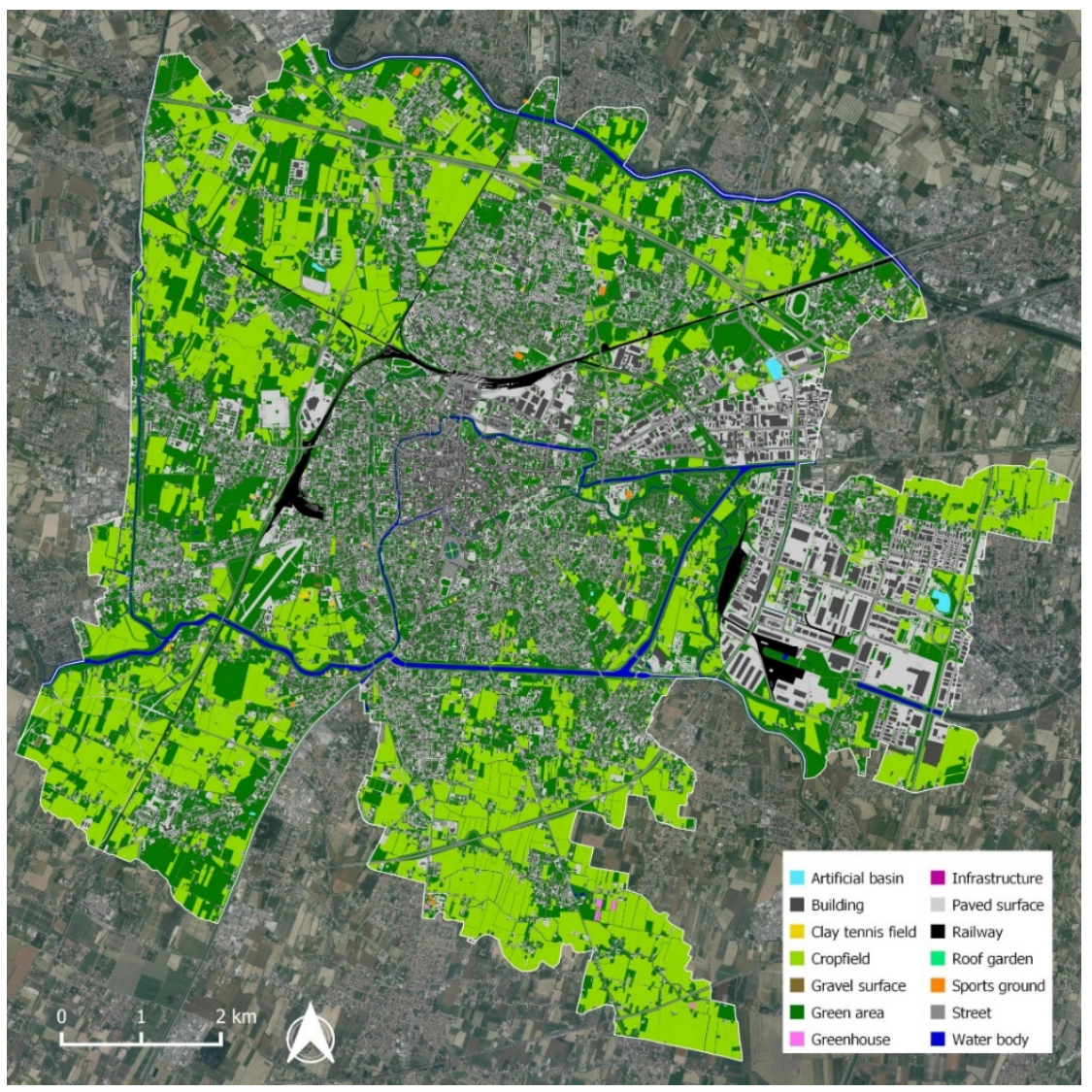

Figure 5. Land use/land cover (LULC) map of Padua based on reclassification of the Topographic DB.

\subsection{Data Validation and Scale-Up Analysis}

We used four sample neighborhoods that represent different types of urban fabric in Padua: San Lazzaro gathers a dense industrial fabric with some brownfields and residual crops; Forcellini is a typical medium to low density residential district with semi-detached houses, often equipped with gardens, and some public parks [44]; Sacra Famiglia and Brentelle are outer districts with a functional mix of rural and residential areas, near to rivers or streams.

In the sample areas, a detailed digital LULC map was derived by visual analysis and manual mapping through QGIS software, using high-resolution orthophotos provided by Veneto Region as the data source and oblique aerial imagery as a support. Thanks to the high geometric resolution of the images, it was possible to extract single geometric features at a variable scale between 1:2000 and 1:1000, going as far as a scale of 1:500 in required cases. The outcome was a polygon vector land cover map for each test area, without holes and overlaps between features. Then, a BAF value between 0 and 1 based on visual interpretation was assigned to each feature [41].

Since LULC mapping and BAF attribution in the sample neighborhoods were highly detailed and controlled by the authors, in this study they are considered as ground truth (Figure 6). 
Table 1. LULC categories of the Topographic DataBase and associated BAF values.

\begin{tabular}{cccc}
\hline DB Class & Definition & LULC Type & BAF \\
\hline A_PED (1) & Pedestrian paths area & Paved surface & 0 \\
A_PED (2) & Pedestrian paths area & Gravel surface & 0.3 \\
A_PVEG & Vegetation-free area & Crop field & 1 \\
AATT (1) & Equipped soil area & Paved surface & 0 \\
AATT (2) & Equipped soil area & Gravel surface & 0.3 \\
AB_CDA & Water course wet area & Water body & 1 \\
AR_STR & Street area & Street & 0 \\
AR_VRD (1) & Green area & Green area & 1 \\
AR_VRD (2) & Green area & Gravel surface & 0.3 \\
ARGINE & Levee & Green area & 1 \\
ATTR_SP (1) & Sport facility & Sports ground & 0 \\
ATTR_SP (2) & Sport facility & Clay tennis field & 0.3 \\
BOSCO & Wood & Green area & 1 \\
CL_AGR & Agricultural area & Crop field & 1 \\
CV_AES & Mining area & Paved surface & 0 \\
DIGA & Dam & Infrastructure & 0 \\
EDIFC (1) & Building & Building & 0 \\
EDIFC (2) & Building & Roof garden & 0.7 \\
MN_EDI (1) & Industrial artefact & Building & 0 \\
MN_EDI (2) & Industrial artefact & Greenhouse & 0.5 \\
MU_SOST (1) & Retaining wall & Paved surface & 0 \\
MU_SOST (2) & Retaining wall & Green area & 1 \\
PS_INC & Pastureland or fallow & Green area & 1 \\
SD_FER & Rail transport track & Railway & 0 \\
SP_ACQ & Pool of water & Artificial basin & 0 \\
SV_AER & Airport zone & Paved surface & 0 \\
SV_STR & Road service area & Paved surface & 0 \\
TRALIC & Pylon & Infrastructure & 0 \\
\hline
\end{tabular}
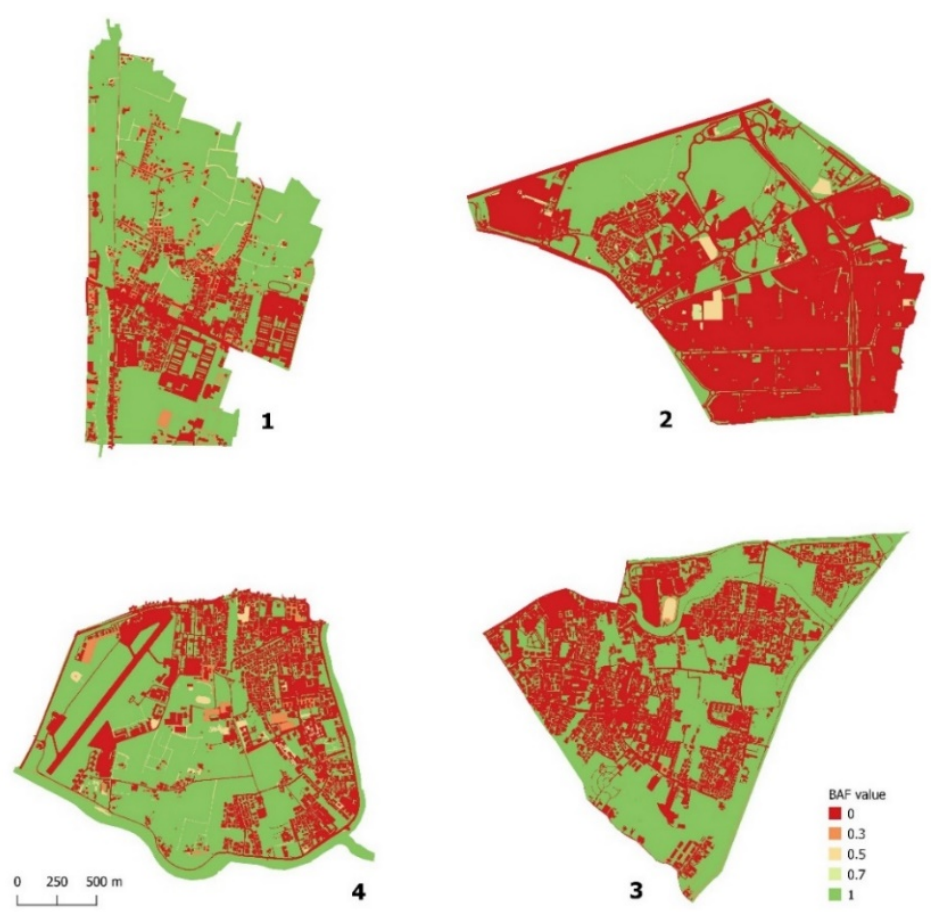

Figure 6. BAF map of the four sample neighborhoods based on visual analysis: (1) Brentelle, (2) San Lazzaro, (3) Forcellini, (4) Sacra Famiglia (see Figure 2). 
At the same time, the municipality-scale LULC map from Topographic DB was clipped to the sample areas and turned into another BAF map of the four neighborhoods (Figure 7), using Table 1 to match BAF values with land cover classes. Then, both the BAF map generated from the DB and the map from visual analysis were rasterized at a $0.5 \mathrm{~m} /$ pixel resolution, using the BAF field in the attribute table as the raster cell value. On each one of the four raster couples, a spatial linear regression was performed using the GRASS GIS function "r.regression.line" within QGIS. To assess spatial correlation between the two mapping procedures, the $\mathrm{R}$ correlation coefficient was considered. The outcomes are displayed in a later section of this paper (see Table 2).
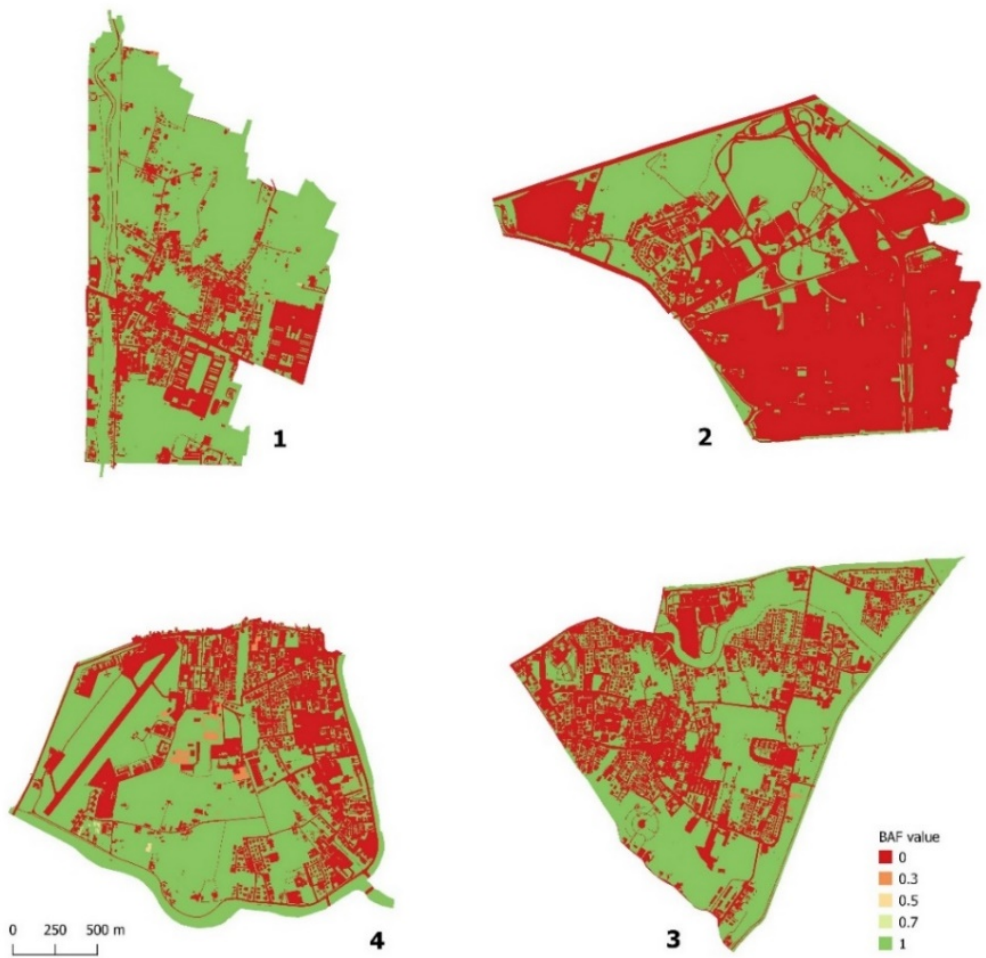

Figure 7. BAF map of the four sample neighborhoods based on Topographic DB: (1) Brentelle, (2) San Lazzaro, (3) Forcellini, (4) Sacra Famiglia (see Figure 2).

To empower the validation process, a confusion matrix for each sample area was calculated in QGIS by the use of the Semi-Automatic Classification Plugin. In this way, we found the percentage of pixels maintaining the same BAF values in maps from DB and from visual analysis (see Tables 3-6). Finally, we determined user's and producer's accuracy of the classifications and kappa coefficients to measure overall agreement [45] (see Table 7).

By a double spatial validation process of the four area samples, we scaled up to the municipality scale by assessing BAF values for all of the Topographic DB features, thus obtaining a BAF map of Padua municipality.

\subsection{Hexagon Tessellation and Geovisualization}

At the end of the main workflow (Figure 4), it is possible to proceed further in order to provide a density BAF map based on a spatial grid. This allows a visual comparison of results from different methods, times, or scales; furthermore, it gives an effective and simple geovisualization of perviousness distribution within the borders of the study area. For this purpose, a hexagon tessellation based on a $1000 \mathrm{~m}^{2}$ cell grid was performed on the Topographic DB.

The DB and the hexagon grid were intersected to generate a new shapefile. On the resulting layer, areas and percentages of each land use feature inside hexagons were calculated. Then, a BAF weight was assigned to land use percentages and the plug-in Groupstats was used to determine the average 
BAF value for each hexagon in the grid. Finally, values were reclassified according to the four main BAF classes, generating a normalized map.

Table 2. Results of spatial linear regressions in the sample neighborhoods.

\begin{tabular}{cc}
\hline Neighborhood & R Value \\
\hline Brentelle & 0.77 \\
Forcellini & 0.75 \\
Sacra Famiglia & 0.82 \\
San Lazzaro & 0.86 \\
\hline
\end{tabular}

Table 3. Error matrix for Sacra Famiglia. Rows = visual analysis; columns = Topographic DB. $\mathrm{UA}=$ user's accuracy; PA = producer's accuracy.

\begin{tabular}{cccccccc}
\hline BAF & $\mathbf{0}$ & $\mathbf{0 . 3}$ & $\mathbf{0 . 5}$ & $\mathbf{0 . 7}$ & $\mathbf{1}$ & TOTAL & PA (\%) \\
\hline 0 & $3,398,947$ & 53,772 & 177 & 0 & 379,242 & $3,832,138$ & 88.7 \\
0.3 & 150,774 & 12,522 & 0 & 0 & 72,120 & 235,416 & 5.32 \\
0.5 & 70,004 & 30,661 & 6059 & 0 & 100,748 & 207,472 & 2.92 \\
0.7 & 14,609 & 2 & 0 & 0 & 20,770 & 35,381 & 0 \\
1 & 440,561 & 24,323 & 6067 & 0 & $6,839,168$ & $7,310,119$ & 93.56 \\
TOTAL & $4,074,895$ & 121,280 & 12,303 & 0 & $7,412,048$ & $11,620,526$ & \\
UA (\%) & 83.41 & 10.32 & 49.25 & $/$ & 92.27 & & \\
\hline
\end{tabular}

Table 4. Error matrix for San Lazzaro. Rows = visual analysis; columns = Topographic DB. UA = user's accuracy; PA = producer's accuracy.

\begin{tabular}{cccccccc}
\hline BAF & $\mathbf{0}$ & $\mathbf{0 . 3}$ & $\mathbf{0 . 5}$ & $\mathbf{0 . 7}$ & $\mathbf{1}$ & TOTAL & PA (\%) \\
\hline 0 & $8,356,056$ & 0 & 0 & 0 & 371,014 & $8,727,070$ & 95.75 \\
0.3 & 550 & 0 & 0 & 0 & 6779 & 7329 & 0 \\
0.5 & 125,144 & 0 & 0 & 0 & 124,673 & 249,817 & 0 \\
0.7 & 23,736 & 0 & 0 & 0 & 47 & 23,783 & 0 \\
1 & 428,879 & 0 & 0 & 0 & $4,366,297$ & $4,795,176$ & 91.06 \\
TOTAL & $8,934,365$ & 0 & 0 & 0 & $4,868,810$ & $13,803,175$ & \\
UA (\%) & 93.53 & $/$ & $/$ & $/$ & 89.68 & & \\
\hline
\end{tabular}

Table 5. Error matrix for Forcellini. Rows = visual analysis; columns = Topographic DB. UA = user's accuracy; PA = producer's accuracy.

\begin{tabular}{cccccccc}
\hline BAF & $\mathbf{0}$ & $\mathbf{0 . 3}$ & $\mathbf{0 . 5}$ & $\mathbf{0 . 7}$ & $\mathbf{1}$ & TOTAL & PA (\%) \\
\hline 0 & $4,250,556$ & 17,689 & 0 & 0 & 963,727 & $5,231,972$ & 81.24 \\
0.3 & 33,831 & 35 & 0 & 0 & 16,480 & 50,346 & 0.07 \\
0.5 & 777 & 0 & 0 & 0 & 38,086 & 38,863 & 0 \\
0.7 & 0 & 0 & 0 & 0 & 0 & 0 & $/$ \\
1 & 451,881 & 8345 & 0 & 0 & $6,112,801$ & $6,573,027$ & 93 \\
TOTAL & $4,737,045$ & 26,069 & 0 & 0 & $7,131,094$ & $11,894,208$ & \\
UA (\%) & 89.73 & 0.13 & $/$ & $/$ & 85.72 & & \\
\hline
\end{tabular}


Table 6. Error matrix for Brentelle. Rows = visual analysis; columns = Topographic DB. UA = user's accuracy; PA = producer's accuracy.

\begin{tabular}{cccccccc}
\hline BAF & $\mathbf{0}$ & $\mathbf{0 . 3}$ & $\mathbf{0 . 5}$ & $\mathbf{0 . 7}$ & $\mathbf{1}$ & TOTAL & PA (\%) \\
\hline 0 & $2,148,168$ & 359 & 1321 & 0 & 391,472 & $2,541,320$ & 84.53 \\
0.3 & 202,053 & 3425 & 0 & 0 & 226,730 & 432,208 & 0.79 \\
0.5 & 37,940 & 6288 & 44 & 0 & 112,160 & 156,432 & 0.03 \\
0.7 & 0 & 0 & 0 & 0 & 0 & 0 & $/$ \\
1 & 370,868 & 3308 & 270 & 0 & $7,044,730$ & $7,419,176$ & 94.95 \\
TOTAL & $2,759,029$ & 13,380 & 1635 & 0 & $7,775,092$ & $10,549,136$ & \\
UA (\%) & 77.86 & 25.6 & 2.69 & $/$ & 90.61 & & \\
\hline
\end{tabular}

Table 7. Overall accuracy and kappa coefficient in the sample neighborhoods.

\begin{tabular}{ccc}
\hline Neighborhood & Overall Accuracy (\%) & Kappa Coefficient \\
\hline Brentelle & 87.18 & 0.75 \\
Forcellini & 87.13 & 0.75 \\
Sacra Famiglia & 88.26 & 0.81 \\
San Lazzaro & 92.17 & 0.85 \\
\hline
\end{tabular}

\section{Results}

\subsection{Spatial Validation and Scale-Up}

To validate the BAF extraction process, a spatial linear regression on BAF raster maps from Topographic DB and from visual analysis was carried out in four sample neighborhoods in Padua (see Section 2.5). Then, the R coefficient values were picked up and compared. Results are shown in Table 2.

As one can see, there is some variability among the neighborhoods. Nevertheless, the correlation level is high enough to be considered significant in each one of the four sample districts.

In order to strengthen the validation process, we calculated error matrices for each couple of BAF maps in the four sample areas (see Tables 3-6). Looking at user's and producer's accuracy, notice how in all the areas BAF classes 0 and 1 have very high percentages-about 80-90\%-whilst intermediate classes, which cover a very modest share of the sample areas, show lower values.

Results of overall accuracy, however, show an elevated percentage of correctly classified pixels in the four areas-all values are greater than $85 \%$, with a peak in San Lazzaro neighborhood, where pixels with the same BAF values are more than $90 \%$ (see Table 7). Kappa coefficients, reported in the same table, show in the sample neighborhoods a value pattern that is similar to $\mathrm{R}$ values (Table 2). Kappa values' range corresponds to a good or very good overall agreement in classifications.

In the end, the outcomes of both spatial linear regression and error matrix calculation legitimize the operation of scale-up performed on the DB.

\subsection{BAF Map of Soil Sealing}

As written in Section 2.5, Table 1 was used to assign BAF values as attributes of the LULC map derived from the Topographic DB. Displaying these values on a green-to-red scale leads to a perviousness map of Padua (Figure 8), in which red represents totally sealed surfaces and green represent totally unsealed surfaces. Looking at the map, some emerging features can be highlighted.

High levels of soil sealing are mainly located inside two urban sections. One is a fuse-shaped zone in a north-south direction, which represents the compact city with dense urban fabric, and includes the old town and the residential districts grown up during the 20th Century. The other major highly impervious zone is the eastern periphery, where the city industrial area and commercial strip are placed. In particular, the industrial area (Zona Industriale Padova, ZIP) looks like a city within the city, with very few pervious spaces between its warehouses and other buildings. 
With respect to pervious surfaces, the historical, triangular-shaped wall system encompassing the urban core and the course of rivers and channels passing through the city are still somehow perceivable as pervious inner belts. Stepping away from the center of the city, notice a periurban ring with a matrix of pervious, mainly agricultural land mixed to sparser urban clusters. This territorial pattern is now crossed and fragmented by the city ring road and its junctions and threatened by low density residential settlements.

The municipality territory, finally, appears to be highly polarized between totally pervious and totally impervious areas (BAF 1 and 0 ). This is mainly due to the fact that municipal territory almost entirely consists of built-up or paved surfaces alternating with green or rural areas. Little importance has so far been given, in Padua urban planning, to intermediate transition surfaces.

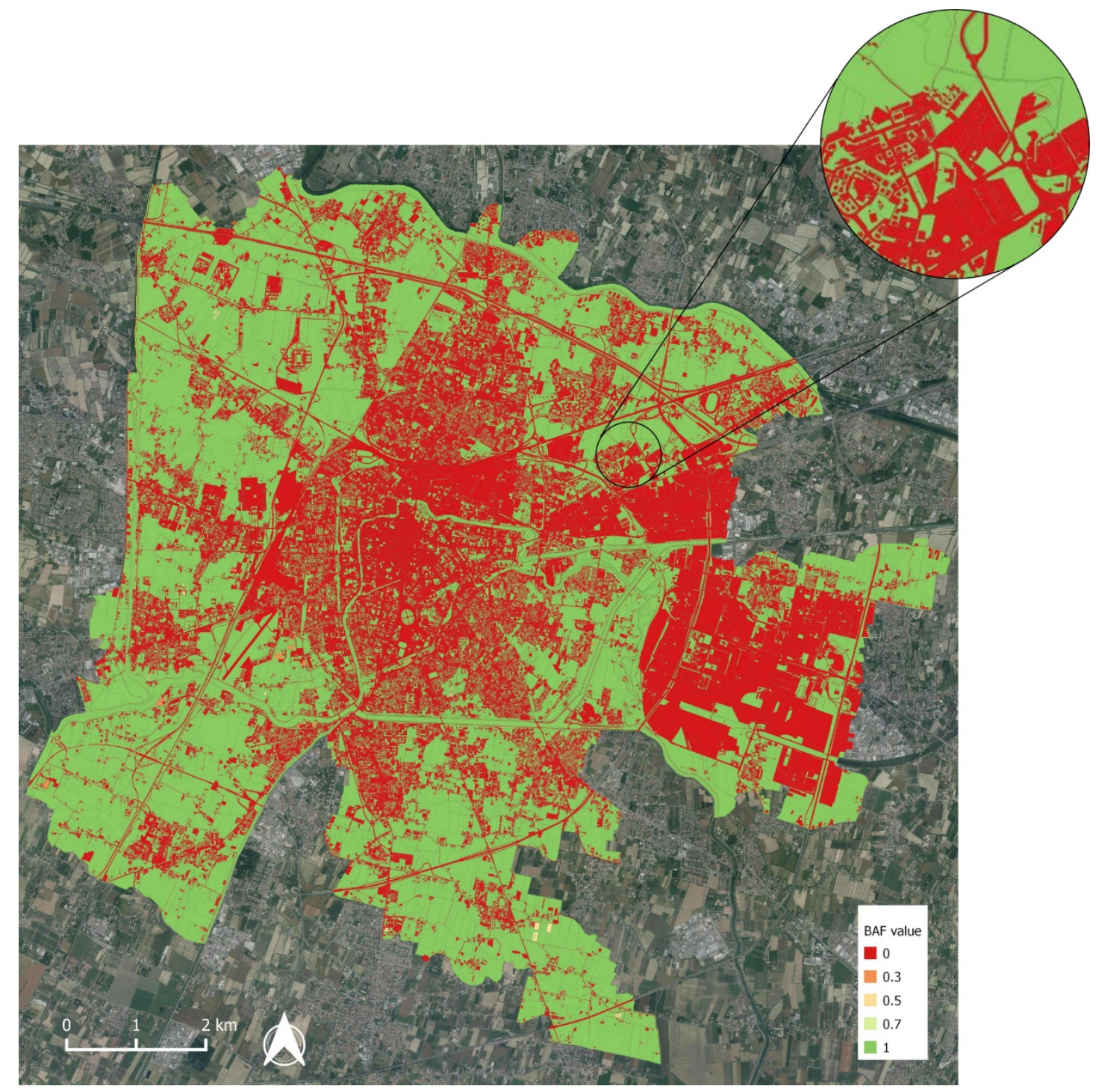

Figure 8. BAF map of Padua based on Topographic DB classes, with a focus on San Lazzaro.

Percentages of surfaces covered by each BAF class are shown in Table 8. 
Table 8. Statistics for BAF values.

\begin{tabular}{ccc}
\hline BAF Value & Area $\left(\mathbf{k m}^{\mathbf{2}}\right)$ & Percentage \\
\hline 0 & 37.78 & 40.30 \\
0.3 & 0.13 & 0.14 \\
0.5 & 0.05 & 0.05 \\
0.7 & 0.00 & 0.00 \\
1 & 55.78 & 59.51 \\
\hline
\end{tabular}

Results show that more than $99 \%$ of features fall into one of the two extreme values: 0 and 1 . This is probably due to the typology of urban surfaces as well as BAF values derived from the original classes of the Topographic DB, which are not differentiated in details. Some intermediate BAF values were obtained by manually splitting some classes—like "pedestrian path area" or "sports facility"-into groups with different BAF values. All the remaining classes, including the most extensive ones like "building" or "agricultural area", were automatically converted by the $0 / 1$ binary BAF scheme. A remarkable datum displayed in Table 8 is the percentage of totally sealed surfaces (BAF value $=0$ ) that covers up to $40.3 \%$ of municipality area. To set a reference for possible future comparisons with other cities, we computed the average BAF index for the whole Padua municipality using the "basic statistics for numeric fields" QGIS function. The result is 0.60 .

For geovisualization purposes, following the hexagon tessellation procedure depicted in Section 2.4 and adopted in Peroni et al. [41], we produced a normalized BAF map with average values of hexagons in a $1000 \mathrm{~m}^{2}$ cell grid (Figure 9). It shows transition areas with intermediate values of perviousness, mainly located around the borders between built-up portions of the city and natural or seminatural soils.

In addition to the perviousness assessment, percentages of reclassified LULC categories were calculated (see Table 9). Here, five main categories cover more than $96 \%$ of the municipality area: green area and crop field are the most extensive pervious classes, whereas paved surface, building, and street are the largest impervious classes.

Table 9. Statistics for LULC categories.

\begin{tabular}{ccc}
\hline LULC Category & Area $\left.\mathbf{( k m}^{\mathbf{2}}\right)$ & Percentage \\
\hline Artificial basin & 0.10 & 0.11 \\
Building & 11.91 & 12.71 \\
Clay tennis field & 0.04 & 0.04 \\
Crop field & 24.33 & 25.95 \\
Gravel surface & 0.09 & 0.10 \\
Green area & 29.77 & 31.76 \\
Greenhouse & 0.05 & 0.05 \\
Infrastructure & 0.00 & 0.00 \\
Paved surface & 14.33 & 15.29 \\
Railway & 1.19 & 1.27 \\
Roof garden & 0.00 & 0.00 \\
Sports ground & 0.06 & 0.06 \\
Street & 10.20 & 10.88 \\
Water body & 1.68 & 1.79 \\
\hline
\end{tabular}




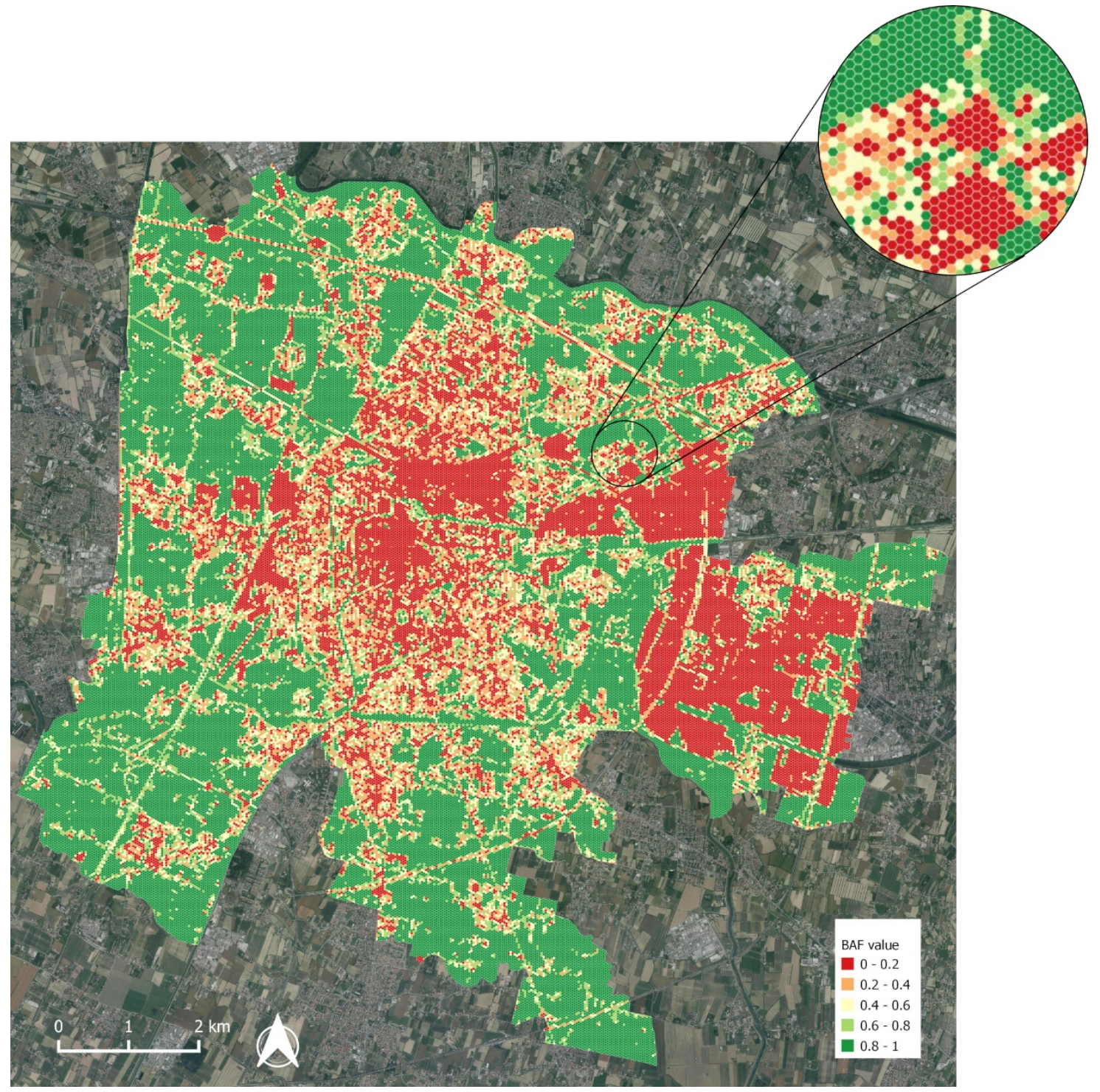

Figure 9. Normalized BAF map of Padua on a $1000 \mathrm{~m}^{2}$ hexagon grid, with a focus on San Lazzaro.

\section{Discussion}

\subsection{Comparing and Monitoring Soil Sealing at Urban Scale}

A further step to evaluate the accuracy of our outcomes may be to compare them with the achievements of existing assessments in the same area. It is worth noting that the Topographic DataBase was published in 2013 - it raises a need to perform a new investigation when source data get updated-so we should seek data from the same period to perform an effective full matching comparison.

Available publications from ISPRA provide municipality-level data for Padua related to year 2007 and since year 2015. For 2007, according to ISPRA, impervious soils in Padua covered $41.3 \%$ of the municipality [46]. In 2017, this value had reportedly reached 49.4\% [23]. Another relevant institute active in soil sealing monitoring is ARPA for Veneto Region (ARPAV). ARPAV published data on soil sealing in Padua for the year 2012; the overall reported percentage is 43.4\% [47].

These data are similar to our study, showing a percentage of totally impervious surfaces resulting from our research, i.e., features with $\mathrm{BAF}=0$, corresponding to $40.3 \%$ of the municipality area. Considering the publication date of the Topographic DB of Padua, this value fits quite well with those reported by ISPRA and ARPAV for the same period. Discrepancies may be due to differences in source LULC maps, in calculation methods, or in imperviousness classification. 
With respect to existing digital maps, BAF allows for detection and visualization of surfaces with intermediate perviousness values. As shown in Section 3.2, the present BAF values in Padua are mostly concentrated in the two extreme classes, 0 and 1 ; however, sustainable planning solutions aiming to drop average perviousness, like green walls or green roofs, would require a comparable BAF classification to properly measure their benefits. Therefore, this study may represent a baseline to monitor the evolution of these planning actions in the city of Padua.

\subsection{BAF Maps for Sustainable Planning: Geovisualizing Scenarios}

A growing need for urban and territorial planning practices respectful of environmental heritage and prioritizing health and equality of citizens is emerging. This is testified by the widespread use of the term "nature-based solutions" in recent academic works and public debates [48-51]. The importance of urban ecosystem services and their sensible management is increasingly recognized by research institutes and public administrations [52,53]. The Green Infrastructure concept and strategy relies on the value of connected vegetated soils or water bodies to plan soft mobility paths or recreational areas.

In this framework, information about location, extension, use, and other attributes of pervious surfaces within city borders is paramount. The concept of BAF index, indeed, relies on the assumption that perviousness of soil is the basis for biological diversity. A BAF mapping at city-level allows a detailed monitoring of land use changes driven by urban development projects or real estate activities. Furthermore, adopting the index to compare actual and planned land use supplies a parameter to measure the environmental impact of plans and projects.

When linked to policies or guidelines focused on the preservation of natural soil, the index can also be used as a benchmark to support sustainable planning strategies [54]. For instance, one planning restriction may be not to increase overall BAF level on a project site. This could lead to good practices like reusing abandoned or decommissioned buildings or complexes, matching new constructions with renaturalization of brownfields or bare soils, and covering buildings with roof gardens or green walls. As written in Section 1.1, pervious soils provide benefits in regulating the water and air cycle, and soil sealing may increase risk of floods by preventing safe water runoff in case of heavy rainfall. Therefore, an in-depth knowledge of BAF values can support environmental risk analysis and assessment based on spatial intersection of permeability, hydrogeological, mobility, and demographic data. Finally, evaluation of soil permeability in different urban districts is important in planning and managing water distribution networks and drainage systems.

In this section, we show two simple cases of overlay analyses in Padua that may be useful to geovisualize possible BAF application scenarios. In the first case (Figure 10), the hexagon tessellation BAF map of Padua was overlapped with a thematic map of hydrogeological instability according to PAT, the territorial management plan for Padua (2014). Hexagons with BAF value lower than or equal to 0.3 were extracted and intersected with selected city sectors. Since the presence of impervious surfaces tends to worsen the effects of intense climatic events, the resulting map may give an idea about the location of higher hydrogeological risk in Padua. If we consider only hexagons entirely falling inside instability zones, there are $10.1 \mathrm{~km}^{2}$ subject to this kind of risk within the municipality borders.

In the second case (Figure 11), we performed an intersection between cells with BAF values higher than or equal to 0.9 and residential areas according to PI, i.e., Padua's current urban development plan. The plan makes no distinction between existing and planned features; however, overlapping areas likely represent residential buildings or complexes to be developed on green or agricultural plots of land, with an expected process of total or partial soil sealing.

Results show that at least $3.1 \mathrm{~km}^{2}$ of mostly pervious areas could be identified in transformations that may imply a loss of soil permeability. Further development of spatial analysis within this framework, for example, involving other classes of Padua PI, may serve as a base for supporting strategies meant to limit, mitigate, or compensate soil sealing. 


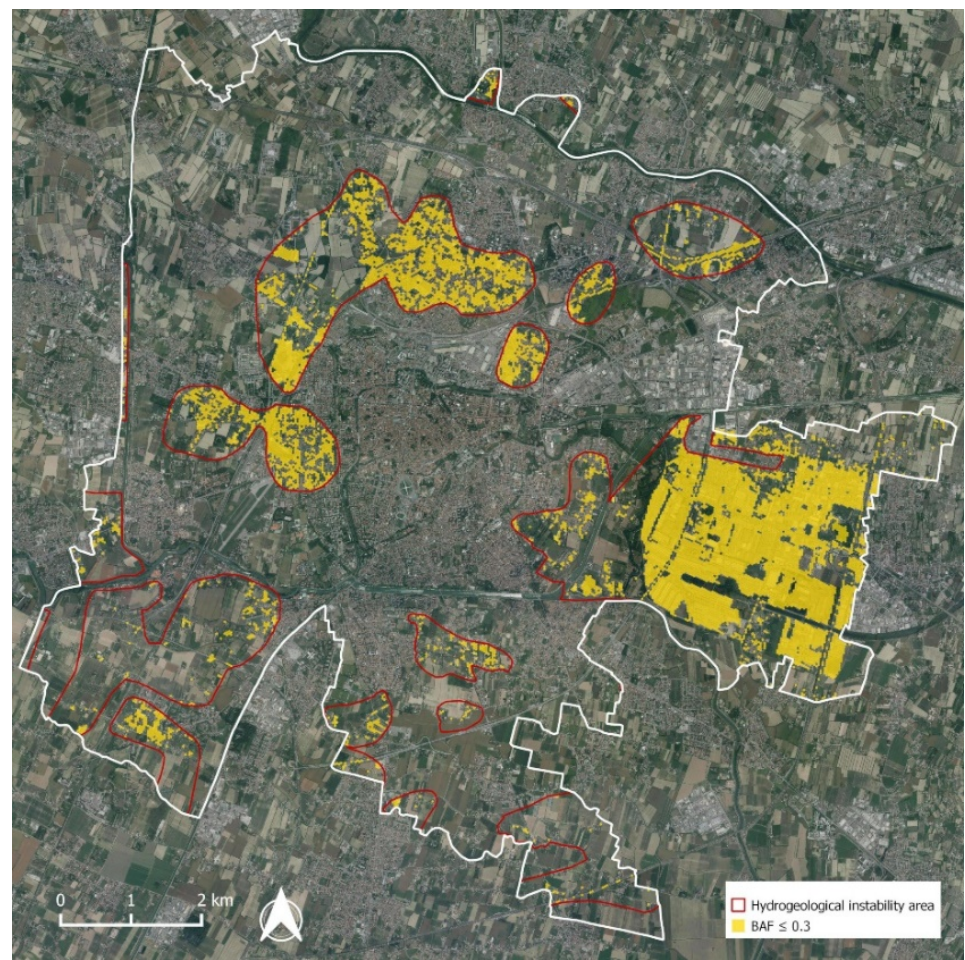

Figure 10. Risk map derived by an overlay between mostly impervious surfaces and areas of hydrogeological instability.

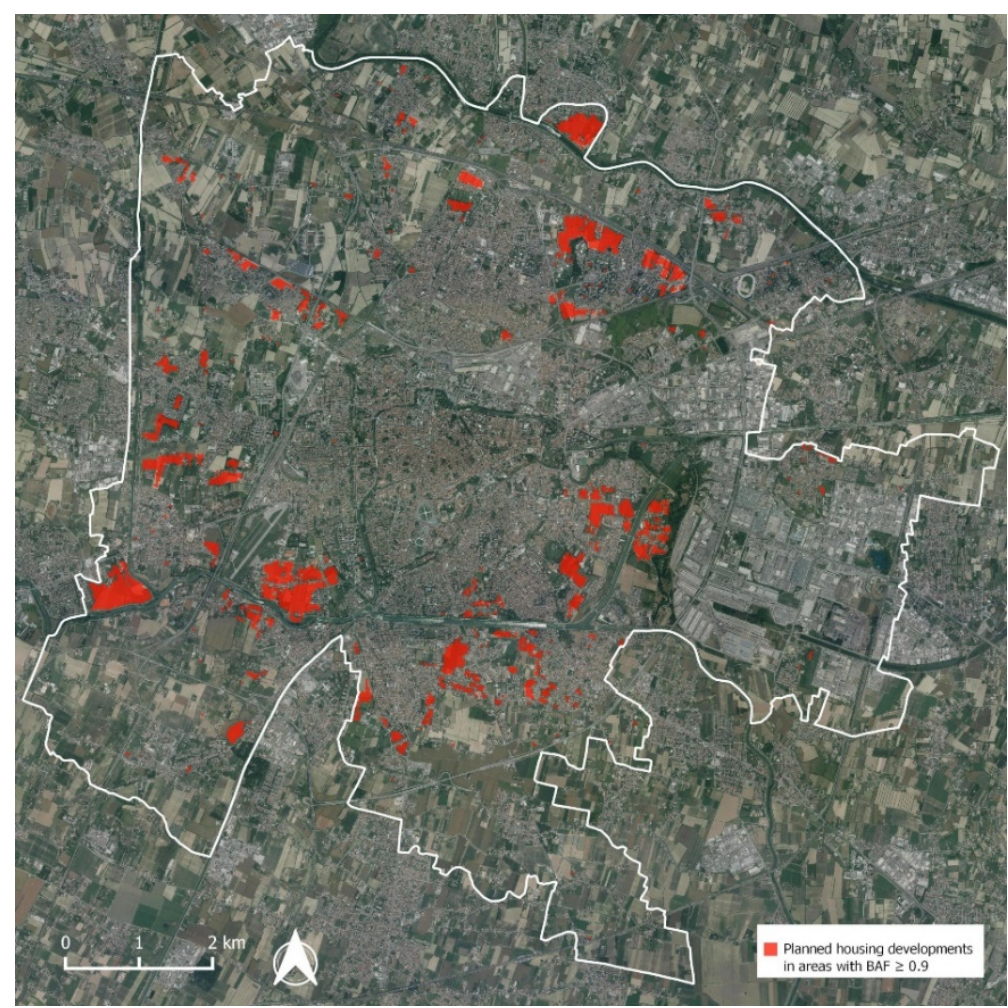

Figure 11. Planned housing developments, according to the urban development plan of Padua, located in areas with BAF values higher than 0.9 . 


\subsection{Data Accuracy and Integration}

First, some description should be provided on the relation between the outcomes of adopted methodology and values provided by monitoring institutes like ISPRA and ARPAV. As we saw, there is no perfect matching among the evaluated research. In particular, results for totally impervious areas coming from our research are slightly lower than the ones used for comparisons.

This could be due to multiple factors. One is some possible minor flaw or inaccuracy in the Topographic DB that served as source data. Validation processes performed on the four sample neighborhoods showed its overall reliability, but some features with BAF value lower than 1 , for example, pedestrian paths inside green areas or gravel plots near to crop fields, may not be recorded on the DB, thus dropping the global average BAF value. However, the discrepancy may also be caused by different research methodology; institutes that work at a regional or national scale mostly rely on satellite imagery (often with a 10 or $30 \mathrm{~m} /$ pixel resolution) as data sources and semi-automatic processing as workflow. This may lead to an overestimation of impervious features at the expense of green or permeable ones.

Another limitation in this study is the need to update the results. Topographic DB was published in 2013. This paper tries to demonstrate the suitability of this procedure in assessing overall perviousness in an urban area; nevertheless, the content of tables on BAF and land cover percentages is possibly different from 2019 values. A clue in this direction is the increased soil sealing in Padua municipality reported by ISPRA in recent years, up to $49.4 \%$ in 2017 [23]. For the specific case of Padua, a solution would be to update manually the DB by visual interpretation, using detailed aerial cartography as spatial data source for detecting and representing land cover changes. The 2018 AGEA/Regione del Veneto orthophoto dataset, with a $20 \mathrm{~cm} /$ pixel resolution, could be a valid data input.

This operation, however, would be very time consuming and would lie beyond the spirit of the work, which is assigning BAF values to an existing, ready-made detailed LULC source. So, whereas the workflow can be considered suitable and replicable, application of well-updated LULC maps, if possible, is recommended.

\subsection{Application Fields and Contributions from other Disciplines}

As we saw, the assessment of soil perviousness in cities can be used in multiple fields and can also support planning or management activities by public administrations. The tools of geographic information science and spatial analysis can help implement studies and applications connecting different disciplines. Furthermore, they can supply simple and powerful geovisualization maps, thus increasing environmental awareness among citizens.

As stated above, well-known examples of cross-cutting contributions involving urban BAF index evaluation are sustainable planning scenarios based on the preservation of permeability surfaces and focused on nature-based solutions or reimagining public spaces and mobility networks. Possible research and/or practices for sustainable urban planning that may take advantage from the application of BAF index include:

Hydrogeological risk assessment. As shown in Figure 10, overlay analysis between a BAF map and a map of instability may ease the detection of flood risk areas and help simulate the runoff effects of extreme rainfall events. This field of application, in particular, may arouse the attention of local administrations and companies managing water supply networks, urban stormwater management, and sewer systems.

Urban planning monitoring. As shown in Figure 11, overlapping areas with higher BAF values and planning indications involving new buildings, infrastructures, or paved surfaces, may help calculate the potential loss of perviousness according to the urban development plan. In order to enhance global perviousness, minimum BAF values to comply in new real estate development projects may be set by planning authorities.

Urban Heat Islands assessment. BAF values may be matched with surface temperatures to detect correlations between soil sealing and urban heat islands. BAF can also stand as an indicator in scenarios 
aiming to prevent or mitigate/compensate the effects of heat islands in urban areas, e. g. renaturalization of soils, implementation of green areas, or installation of green roofs for microclimate regulation.

Ecosystem services assessment. Spatial diachronic analysis of perviousness involving BAF calculation on historical maps or imagery may be an effective investigation tool to quantify both environmental and economic impacts related to land use changes and soil sealing. Moreover, scenarios for enhancing urban ecosystem services such as green infrastructures or other nature-based solutions may set the improvement of average soil permeability as one of their goals, and therefore use present and future BAF calculation to measure predicted changes.

Depending on the scale of the study, different procedures to assess soil perviousness can be adopted; a reclassification of existing detailed LULC maps is an optimum solution when source data are updated and cover all the study area. Digital mapping based on visual analysis can provide very accurate results, but since it is very time consuming, it is only suitable for small scales. For large study areas, extracting land cover classes by supervised or unsupervised classification of remote sensing data is likely the most appropriate procedure.

\section{Conclusions}

Soil sealing is widely considered a major issue affecting ecosystem services provided by natural or seminatural soils $[1,3,7]$. Its multiscale monitoring is a primary tool in support of sustainable urban and territorial planning policies in Italy and Europe [2,17,21,22].

In this framework, our work mapped and assessed soil sealing at municipality scale in Padua, one of the Italian cities most affected by this issue [23]. By using the BAF urban ecological index, we mapped and estimated soil sealing in Padova, by modelling and validating the municipal Topographic DataBase of the Municipality of Padua. Our study showed that the most sealed surfaces are located in the southernmost sector of the city, where the city industrial area and commercial strip are situated, and in the inner city, which includes the old town and the residential districts that have grown up during the 20th Century. We also calculated an average BAF index value of 0.6. Our results are similar to other analyses performed by national or regional institutes, such as ISPRA and ARPA. Moreover, the output of the hexagon tessellation provides an effective geovisualization tool.

Limitations of this research approach may be related to the update of source database and the need to simplify original LULC classes, which may lead to some loss of accuracy in BAF mapping. Solutions would require the commitment of public spatial data producers in conjunction with researchers and monitoring institutes.

As for future developments, BAF classification and mapping can serve as a tool in urban or territorial planning studies. Following the example of Berlin Municipality [32], setting minimum values could be adopted for new construction projects, thus fuelling mitigation scenarios like rooftop greening [38]. BAF could also be used in the fields of climate adaptation or hydrogeological risk assessment $[48,49,54]$. Finally, this work could stand as a basis for comparative evaluations involving other Italian or European municipalities having a similar LULC database.

Author Contributions: This paper is the result of discussions and analysis conducted by the seven authors (G.P., F.P., S.E.P., D.C., A.G.C., A.M., and M.D.M.) who equally contributed to the final assemblage of the ideas and concepts contained in this paper. All authors have read and agreed to the published version of the manuscript.

Funding: This research was supported by the Innovative Projects Program for students 2019-2020. "Walking Parks" (DAFNAE), University of Padua (Italy).

Acknowledgments: The authors wish to thank everyone who contributed in the work that led to this paper, and in particular: Edoardo Crescini for his work on Forcellini neighborhood; Daniele Zago for his work on Brentelle neighborhood; Francesco Ferrarese for his technical advice.

Conflicts of Interest: The authors declare no conflict of interest. 


\section{References}

1. Aksoy, E.; Gregor, M.; Schröder, C.; Löhnertz, M.; Louwagie, G. Assessing and Analysing the Impact of Land Take Pressures on Arable Land. Solid Earth 2017, 8, 683-695. [CrossRef]

2. Tobias, S.; Conen, F.; Duss, A.; Wenzel, L.M.; Buser, C.; Alewell, C. Soil Sealing and Unsealing: State of the Art and Examples. Land Degrad. Dev. 2018, 29, 2015-2024. [CrossRef]

3. Scalenghe, R.; Ajmone Marsan, F. The Anthropogenic Sealing of Soils in Urban Areas. Landsc. Urban Plan. 2009, 90, 1-10. [CrossRef]

4. Artmann, M.; Breuste, J. Cities Built for and by Residents: Soil Sealing Management in the Eyes of Urban Dwellers in Germany. J. Urban Plan. Dev. 2015, 141, A5014004. [CrossRef]

5. Behnisch, M.; Poglitsch, H.; Krüger, T. Soil Sealing and the Complex Bundle of Influential Factors: Germany as a Case Study. ISPRS Int. J. Geo Inf. 2016, 5, 132. [CrossRef]

6. Ceccarelli, T.; Bajocco, S.; Salvati, L.; Perini, L. Investigating Syndromes of Agricultural Land Degradation through Past Trajectories and Future Scenarios. Soil Sci. Plant Nutr. 2014, 60, 60-70. [CrossRef]

7. Gardi, C. (Ed.) Urban Expansion, Land Cover and Soil Ecosystem Services; Routledge: London, UK; Boston, MA, USA, 2017. [CrossRef]

8. Leemans, R.; De Groot, R.S. Conceptual Framework Working Group of the Millennium Ecosystem Assessment. In Ecosystems and Human Well-being. A Framework for Assessment; Island Press: Washington, DC, USA, 2003.

9. Costanza, R.; De Groot, R.; Braat, R.; Kubiszewski, I.; Fioramonti, L.; Sutton, P.; Farber, S.; Grasso, M. Twenty years of ecosystem services: How far have we come and how far do we still need to go? Ecosyst. Services 2017, 28, 1-16. [CrossRef]

10. Hassan, R.; Scholes, R.; Ash, N. Ecosystems and Human Well-being: Current State and Trends, Findings of the Condition and Trends Working Group of the Millennium Ecosystem Assessment; Island Press: Washington, DC, USA, 2005; Volume 1.

11. Haines-Young, R.; Potschin, M. Common International Classification of Ecosystem Services (CICES): Consultation on Version 4, August-December 2012. 2013. Available online: www.cices.eu (accessed on 18 April 2020).

12. Tavares, P.A.; Beltrão, N.; Guimarães, U.S.; Teodoro, A.; Gonçalves, P. Urban Ecosystem Services Quantification through Remote Sensing Approach: A Systematic Review. Environments 2019, 6, 51. [CrossRef]

13. Luederitz, C.; Brink, E.; Gralla, F.; Hermelingmeier, V.; Meyer, M.; Niven, L.; Panzer, L.; Partelow, S.; Rau, A.-L.; Sasaki, R.; et al. A review of urban ecosystem services: Six key challenges for future research. Ecosyst. Services 2015, 14, 98-112. [CrossRef]

14. Baer, S.G.; Birgé, H.E. Soil ecosystem services: An overview. In Managing Soil Health for Sustainable Agriculture. Fundamentals; Don, R., Ed.; Burleigh Dodds Science Publishing: Cambridge, UK, 2018; Volume 1, E.-chapter.

15. Plieninger, T.; Dijks, S.; Oteros-Rozas, E.; Bieling, C. Assessing, mapping, and quantifying cultural ecosystem services at community level. Land Use Policy 2013, 33, 118-129. [CrossRef]

16. Hennig, E.I.; Schwick, C.; Soukup, T.; Orlitová, E.; Kienast, F.; Jaeger, J.A.G. Multi-scale analysis of urban sprawl in Europe: Towards a European de-sprawling strategy. Land Use Policy 2015, 49, 483-498. [CrossRef]

17. Prokop, G.; Jobstmann, H.; Schönbauer, A. Report on Best Practices for Limiting Soil Sealing and Mitigating Its Effects, European Commission Technical Report. 2011. Available online: https:/ec.europa.eu/environment/ archives/soil/pdf/sealing/Soil\%20sealing\%20-\%20Final\%20Report.pdf (accessed on 21 April 2020).

18. Pileri, P. Che Cosa c'è Sotto. Il Suolo, I Suoi Segreti, le Ragioni per Difenderlo; Altreconomia: Milano, Italy, 2016.

19. Langanke, T. Copernicus Land Monitoring Service-High Resolution Layer Imperviousness. 2016. Available online: https://land.copernicus.eu/user-corner/technical-library/hrl-imperviousness-technical-documentprod-2015 (accessed on 26 January 2019).

20. European Environmental Agency. Imperviousness and Imperviousness Change. 2017. Available online: https://www.eea.europa.eu/data-and-maps/indicators/imperviousness-change-1/assessment (accessed on 9 September 2019).

21. Munafò, M.; Marinosci, I.; Tombolini, I.; Salvati, L. Il monitoraggio del consumo di suolo in Italia. Bollettino. AIC 2013, 149, 117-128.

22. Munafò, M.; Salvati, L.; Zitti, M. Estimating soil sealing rate at national level-Italy as a case study. Ecolog. Indicat. 2013, 26, 137-140. [CrossRef] 
23. Munafò, M. (Ed.) Consumo di Suolo, Dinamiche Territoriali e Servizi Ecosistemici. Edizione 2018; Ispra: Roma, Italy, 2018.

24. Diksha, A.K. Analysing urban sprawl and land consumption patterns in major capital cities in the Himalayan region using geoinformatics. App. Geograp. 2017, 89, 112-123. [CrossRef]

25. García, P.; Pérez, E. Mapping of soil sealing by vegetation indexes and built-up index: A case study in Madrid (Spain). Geoderma 2016, 268, 100-107. [CrossRef]

26. Iovino, G. Le fonti informative per il monitoraggio del consumo di suolo. Bollettino. A.I.C. 2014, 152, 36-55.

27. Gerundo, R.; Grimaldi, G. The Measure of Land Consumption Caused by Urban Planning. Procedia Engineering 2011, 21, 1152-1160. [CrossRef]

28. Salvati, L.; Carlucci, M. Distance matters: Land consumption and the mono-centric model in two southern European cities. Landsc. Urb. Plann. 2014, 127, 41-51. [CrossRef]

29. Xiong, C.; Tan, R. Will the land supply structure affect the urban expansion form? Habitat Int. 2018, 75, 25-37. [CrossRef]

30. Casella, V.; Franzini, M.; De Lotto, R. Geomatics for smart cities: Obtaining the urban planning BAF index from existing digital maps. Int. Arch. Photogramm. Remote Sens. Spat. Inf. Sci. 2016, 41, 689-694. [CrossRef]

31. De Lotto, R.; Casella, V.; Franzini, M.; Gazzola, V.; Morelli di Popolo, C.; Sturla, S.; Venco, E.M. Estimating the Biotope Area Factor (BAF) by Means of Existing Digital Maps and GIS Technology. In Computational Science and Its Applications-ICCSA 2015; Springer International Publishing: Cham, Switzerland, 2015; pp. 617-632.

32. Becker, G.; Mohren, R. The Biotope Area Factor as an Ecological Parameter; Landschaft Planen \& Bauen: Berlin, Germany, 1990.

33. Song, B.-H.; Kil, S.-H. Research Trends for Improvement of Biotope Area Index. J. People Plants Environ. 2018, 21, 103-116. [CrossRef]

34. ISTAT. Population Data by Municipality. Available online: http://demo.istat.it/pop2019/index.html (accessed on 10 September 2019).

35. Fadini, U. (Ed.) Mura di Padova. Guida al Sistema Bastionato Rinascimentale; Edibus: Vicenza, Italy, 2013.

36. Marzari, S. (Ed.) Padova e la Città Metropolitana. 1807-2007 la Metamorfosi del Paesaggio Urbano; I Antichi Editori Venezia: Venezia, Italy, 2008.

37. Lakes, T.; Kim, H.O. The urban environmental indicator "Biotope Area Ratio"-An enhanced approach to assess and manage the urban ecosystem services using high resolution remote-sensing. Ecol. Indic. 2012, 13, 93-103. [CrossRef]

38. Regione del Veneto. Segreteria Regionale all'Ambiente e Territorio, Unità di Progetto per il SIT e la Cartografia, DB Topografico Versione 2.6; Sistema Bibliotecario di Ateneo: Bologna, Italy, 2010.

39. European Commission. Directive 2007/2/EC of the European Parliament and of the Council of 14 March 2007 establishing an Infrastructure for Spatial Information in the European Community (INSPIRE); European Commission: Brussels, Belgium, 2007.

40. Metadata for Topographic DataBase of Padua Municipality. Available online: https://geodati.gov.it/ geoportale/ (accessed on 18 April 2020).

41. Peroni, F.; Pristeri, G.; Codato, D.; Pappalardo, S.E.; De Marchi, M. Biotope Area Factor: An Ecological Urban Index to Geovisualize Soil Sealing in Padua, Italy. Sustainability 2020, 12, 150. [CrossRef]

42. Comune di Padova. Piano di Assetto del Territorio. Norme Tecniche di Attuazione; Comune di Padova: Padova, Italy, 2014.

43. Comune di Padova. Piano Degli Interventi. Norme Tecniche di Attuazione; Comune di Padova: Padova, Italy, 2018.

44. Di Montevecchio, C.; Benedetti, E. Consumo di suolo a Padova: Analisi GIS del quartiere Forcellini (PD) e calcolo dell'indice Biotope Area Factor. Bachelor's Thesis, Degree Course in Environmental Sciences, Department of Biology, University of Padova, Padova, Italy, 2018.

45. Banko, G. A Review of Assessing the Accuracy of Classifications of Remotely Sensed Data and of Methods Including Remote Sensing Data in Forest Inventory. IIASA Interim Report; IIASA: Laxenburg, Austria, 1998.

46. Munafò, M.; Tombolini, I. Il Consumo di Suolo in Italia. Edizione 2014; ISPRA: Roma, Italy, 2014.

47. ARPAV. Data about Land Consumption. 2012. Available online: http://www.arpa.veneto.it/arpavinforma/ indicatori-ambientali/indicatori_ambientali/geosfera/indicatori-ambientali-del-veneto/geosfera/uso-delterritorio/consumo-di-suolo-agg.-2012 (accessed on 12 September 2019). 
48. Geneletti, D.; Zardo, L.; Cortinovis, C. Promoting Nature-Based Solutions for Climate Adaptation in Cities Through Impact Assessment. In Handbook on Biodiversity and Ecosystem Services in Impact Assessment; Davide, G., Ed.; Edward Elgar Publishing: Cheltenham, UK, 2003; Chapter 18; pp. 428-452.

49. Davies, C.; Lafortezza, R. Transitional path to the adoption of nature-based solutions. Land Use Policy 2019, 80, 406-409. [CrossRef]

50. Faivre, N.; Fritz, M.; Freitas, T.; de Boissezon, B.; Vandewoestijne, S. Nature-Based Solutions in the EU: Innovating with nature to address social, economic and environmental challenges. Environ. Res. 2017, 159, 509-518. [CrossRef] [PubMed]

51. Keesstra, S.; Nunes, J.; Novara, A.; Finger, D.; Avelar, D.; Kalantari, Z.; Cerdà, A. The superior effect of nature based solutions in land management for enhancing ecosystem services. Sci. Total Environ. 2018, 610-611, 997-1009. [CrossRef] [PubMed]

52. European Commission. Guidelines on Best Practice to Limit, Mitigate or Compensate Soil Sealing; European Commission: Brussels, Belgium, 2012. [CrossRef]

53. Ginzky, H.; Heuser, I.L. International Yearbook of Soil Law and Policy 2018; Springer: Berlin, Germany, 2019; Volume MMXVIII. [CrossRef]

54. Dizdaroglu, D.; Yigitcanlar, T.; Dawes, L.A. Sustainable Urban Futures: An Ecological Approach to Sustainable Urban Development. Proceedings of the Second Infrastructure Theme Postgraduate Conference 2009: Rethinking Sustainable Development-Planning, Infrastructure Engineering, Design and Managing Urban Infrastructure, Queensland, Australia, 26 March 2009; Queensland University of Technology: Brisbane, Australia, 2009.

(C) 2020 by the authors. Licensee MDPI, Basel, Switzerland. This article is an open access article distributed under the terms and conditions of the Creative Commons Attribution (CC BY) license (http://creativecommons.org/licenses/by/4.0/). 